\title{
At the Crossroads: An IALP Perspective
}

\author{
Ewa Söderpalm \\ Göteborg University, Göteborg, Sweden
}

It is hard to believe that my 3-year term as IALP President is now completed, years that have comprised so much hard work, such a lot of fun, friendship and pleasure, but also some frustration. The frustration may not be as negative as it sounds, however, as it also contains a promise about the great potentials for the future of our Association. Let me come back to that later on.

IALP is a fantastic organisation! Just imagine a world society that without discrimination with respect to race, gender, religion or cultural differences offers a platform for people all over the world to share knowledge and form networks based on professional needs and friendship. This is also a wonderful chance of finding out how much we really have in common regardless of linguistic and cultural differences in our common efforts to assist people with communication disorders.

IALP is an old venerable association. In 1999 , it celebrated its 75 th anniversary with the Göteborg Composium, where many distinguished scholars were invited to present the state of the art within the various IALP domains. Just before the anniversary, the fourth edition of the IALP History was published thanks to the dedicated work of many IALP members. This is indeed interesting

\begin{tabular}{ll}
\hline KARGER & ( 2002 S. Karger AG, Basel \\
Fax +41 61306 1234 & $1021-7762 / 02 / 0542-0063 \$ 18.50 / 0$ \\
$\begin{array}{l}\text { E-Mail karger@karger.ch } \\
\text { www. karger.com }\end{array}$ & $\begin{array}{l}\text { Accessible online at: } \\
\text { www.karger.com/journals/fpl }\end{array}$
\end{tabular}

reading, where the growth of the Association can be followed from its foundation in 1924 . The 2001 congress in Montreal will be the 25th one and with the next congress in Brisbane, Australia, all continents will have hosted at least one IALP congress, thereby stressing the globality of the Association.

Serving in an established organisation in many ways means challenges. It goes without saying that many traditions that have developed over the years within IALP reflect different ways of looking at things and ways that are not very suitable for our modern world and our way of thinking. We certainly must take advantage of new techniques that in so many ways can improve and also certainly have improved our work in IALP, but we must be careful in our efforts to modernise, so that we do not cut the links to the past. I think we owe that to our predecessors.

One of the challenges and also one of the frustrations is to make IALP better known. As it now is, IALP is both too big and too small. The organisation is too big to be run exclusively on a voluntary basis, if we want to live up to our ambitious plans. It is too small to afford projects that require a substantial financial support. We need to grow and to inform colleagues all over the world about Ewa Söderpalm
Department of Logopedics and Phoniatrics
Göteborg University, Box 452
SE-405 30 Göteborg (Sweden) 
IALP and its possibilities. So it is my belief that we are now at a crossroads, where we need changes for a successful future. According to our Bylaws, all people serving the organisation shall do this on a voluntary basis. This has worked well in the past, but modern life with Board members who mostly work more than full time at their hospitals, schools, centres and universities can hardly be expected to put in many hours into the organisation out of their free time that is so very scarce. This may lead to a slowing down of the activities in the standing committees of IALP. Much valuable work has been and is still being carried out by many dedicated members of these committees. Let me just mention a few: the symposia organised by the Aphasia Committee and its publications, the guidelines for initial education in logopaedics and guiding principles for the training of workers in less served areas written by the Education Committee and a help and support to many new and old training centres in many countries.

In many ways, I consider the committees the real backbone of IALP. Here you find members representing outstanding competence within virtually all the IALP areas. Let us hope that in the future, they can be offered more financial and administrative support. I think the near future will see the beginning of an IALP office with at least one paid employee. This will hopefully mean increased support to the Board and committees and also act as a guarantee for continuity, which is sometimes difficult with regular changing of Board members.

Let us hope that this change will only be for the better and will help us keep many of our old traditions. One of the purposes of IALP is to plan for the triennial congresses. The congress is always organised by a congress committee in the host country, and this committee is also economically responsible for the outcome. This committee can arrange the congress very much as it wishes, which will make it possible for the regular IALP congress attendee to meet different cultures and benefit from various local traditions etc. There are, however, some parts that the IALP Board is responsible for and that have to be handled according to the Bylaws. For instance, every IALP member is entitled to propose subjects for main congress reports and also has the right to cast a vote on three possible main reports for the next congress. This procedure might not strike anyone as the easiest or most logical way of organising a congress, but it certainly is very democratic and I hope we will keep it as it is certainly part of old IALP traditions that in a way can be said to capture the soul of our old Association.

It is with an enormous gratitude, I now look back at my years on the IALP Board - my 3 years as President and before that as secretary and member of the Board. I have made the acquaintance of so many fascinating people who have given me so much of friendship and generous sharing of professional knowledge.

My appreciation goes specifically to the people I have worked close to in various capacities. The work in the executive committee is very much a team work - not always easy - as our ways of handling matters may differ in different parts of the world and will bring forward compromises. But I think the work fosters humbleness and an awareness that matters can be handled in various ways, and procedures well known 'from home' are not always the only possible ones and not even the best ones. This is very much what international work has meant to me, and I wish that many IALP members will have the opportunity of serving terms on the Board or in one of the standing committees.

I leave knowing that IALP will be in good hands and I wish the next executive committee and Board the very best for the future.

Thank you all!

Ewa Söderpalm 